\title{
Ensino de geologia introdutória: raízes e desdobramentos da mudança curricular em 1973 na USP
}

\author{
Ivan Amorosino do Amaral \\ (Faculdade de Educação-Unicamp)
}

\begin{abstract}
CURRICULAR CHANGE IN HIGH SCHOOL INTRODUCTORY GEOLOGY TEACHING: ROOTS AND DEVELOPMENTS FROM THE CURRICULUM CHANGE. The curriculum change in teaching introductory geology at the undergraduate level, as performed out at the Institute of Geosciences, University of São Paulo, in the early 1970s, had its roots in the previous decade and many developments in the subsequent decades. Among the roots are: an international revision on the epistemological status of geological science, new national and international educational ideas about teaching and learning, the american curriculum design, known in Brazil as the project "Investigating the Earth", adapted to our country by the Brazilian Foundation for the Development of Science Teaching, and spread out mainly by the Training Center for Teachers of Science of the State of São Paulo and short undergraduate courses for Science Teachers. Among its consequences, are: the creation of a National Commission on Teaching within the Brazilian Society of Geology, in the 1970s, the Specialization Course in Higher Education of Geosciences in the late 1970s and in the following two decades, the national movement for curricular change for undergraduate courses in Geology, settled on a diagnostic research and deliberations on national Symposiums, the institutionalization of a research group on Teaching of Geosciences at the newly created Institute of Geosciences, University of Campinas, in the 1980s, which was consolidated in a specific department and an MA and PhD graduate programs in the area of education. The group has also exerted a noticeable influence on curriculum reform of first grade science teaching in the state of São Paulo, in the 1980s. Citation: Amaral I.A.do. 2014. Raízes da mudança curricular ocorrida em 1973 na USP. Terræ Didatica, 10(3):161-170. http://www.ige.unicamp.br/terraedidatica/.
\end{abstract}

KEYWORDS: Geoscience teaching; curriculum innovation, introductory geology; history.

RESUMO A mudança curricular no ensino de geologia introdutória no nível superior, levada a efeito no Instituto de Geociências da Universidade de São Paulo na década de 70 passada, teve suas raízes na década anterior e diversos desdobramentos nas décadas subsequentes. Entre as raízes, destacam-se: as reflexões internacionais sobre o status epistemológico da ciência geológica; novas idéias pedagógicas nacionais e internacionais sobre o ensino e a aprendizagem; o projeto curricular norte-americano, conhecido no Brasil como Investigando a Terra, adaptado para o nosso país pela Fundação Brasileira para o Desenvolvimento do Ensino de Ciências, difundido principalmente pelo Centro de Treinamento de Professores de Ciências do Estado de São Paulo e pelas Licenciaturas Curta em Ciências. Entre seus desdobramentos, destacam-se: a criação de uma Comissão Nacional de Ensino no interior da Sociedade Brasileira de Geologia, na década de 70; o Curso de Especialização em Ensino Superior de Geociências, no final da década de 70 e nas duas décadas seguintes; o movimento nacional de mudança curricular da graduação em Geologia, assentado em pesquisas diagnósticas e deliberado em Simpósios Nacionais; a institucionalização de um grupo de pesquisa em ensino de Geociências, no recém-criado Instituto de Geociências da Universidade de Campinas, na década de 80, que se consolidou em um Departamento específico e um mestrado e doutorado na área de ensino; influência marcante em reforma curricular do ensino de Ciências no $1^{\circ}$ Grau no estado de São Paulo, na década de 1980.

PALAVRAS-CHAVE: Ensino de Geociências; inovação curricular; geologia introdutória; perspectiva histórica. 


\section{Introdução}

No $1^{\circ}$ semestre letivo de 1973 , a disciplina básica de Geologia oferecida pelo Instituto de Geociências da Universidade de São Paulo (IG-USP), designada na época pela sigla GGG-121, sofreu radicais mudanças em seu corpo docente, nos seus objetivos educacionais, no conteúdo programático, na metodologia do ensino, bem como nos critérios constitutivos das suas diferentes turmas. Oferecida em caráter obrigatório para alunos de Geologia, Geografia e Ciências Biológicas, assim como em caráter optativo para outros cursos da universidade, particularmente Física, Química e Matemática, tinha uma carga horária de 60 horas, distribuídas em quatro horas semanais durante um semestre, sendo oferecida nos dois semestres letivos, perfazendo dez turmas anuais, desenvolvidas algumas no período diurno e outras no noturno, perfazendo cerca de 500 alunos por ano. A disciplina passou a ser coordenada na ocasião por um professor convidado pela direção do Instituto, especializado no ensino de geologia introdutória no nível superior, que não pertencia até então ao seu corpo docente, ao qual foi concedida autonomia para realizar todas as mudanças necessárias para superar a crise que a disciplina então vivia e que motivara a iniciativa de produzir as mencionadas mudanças. Nos anos que se seguiram, a experiência repercutiu para além das fronteiras da USP e extravazou o âmbito da Geologia Introdutória, contribuindo para novas mudanças no ensino da geologia no país. O referido coordenador da experiência inovadora da USP é o autor da presente comunicação.

Estes acontecimentos, sucintamente apresentados, necessitam ser esclarecidos, tanto no que se refere às condições que favoreceram as suas origens, quanto aos principais contornos que foram adquirindo ao longo do tempo. Neste sentido, emergem algumas questões pertinentes: Por que foi deflagrada essa mudança? Que condições foram oferecidas para a sua implementação? Em que fontes se inspirou o realinhamento programático-metodológico? Que fatos e episódios importantes concorreram para a adoção e o sucesso da nova proposta de ensino adotada? Quem foram seus principais atores? Que contribuições diretas e indiretas a experiência inovadora da USP forneceu para o ensino de Geociências no Brasil?

A finalidade desta comunicação é resgatar as origens históricas da inovação curricular colocada em prática no Instituto de Geociências da USP, a partir de 1973, no âmbito do ensino da geologia introdutória, bem como descrever suas principais características, além de enunciar alguns dos seus desdobramentos relevantes no ensino do conteúdo geológico em nosso país nos anos que se seguiram. Tomaremos as indagações acima como norteadoras da narrativa e das reflexões que se seguem, buscando inicialmente suas raízes na década anterior àquela em que os fatos focalizados foram deflagrados.

\section{Resgate dos principais fatores, nos Anos 60 do século passado}

Muitas das mudanças em questão podem ser relacionadas à criação do Instituto Brasileiro de Educação, Ciência e Cultura (IBECC), ocorrida em 1946, na cidade de São Paulo, e à expansão das suas atividades a partir da década de 1950, voltadas precipuamente para a renovação do ensino de Ciências, nos níveis correspondentes ao ensino fundamental atual. Equipes especializadas, ligadas a essa instituição, voltaram seus esforços para a produção de textos e kits de materiais didáticos, tendo em vista reverem os conteúdos programáticos convencionais e tornarem o ensino mais prático, por intermédio de atividades didáticas de cunho experimental a serem desenvolvidas pelos alunos. Diversos desses projetos de renovação eram originais, enquanto outros se inspiravam em projetos curriculares estrangeiros (particularmente norte-americanos) ou representavam meras adaptações dos mesmos à realidade brasileira. (Amaral 1995)

Essas iniciativas eram facilitadas pelos vínculos do IBECC com a Organização dos Estados Americanos (OEA), com a Organização das Nações Unidas para a Educação, a Ciência e a Cultura (UNESCO), com a Fundação Ford e outras organizações congêneres. Tais colaborações foram fortalecidas a partir da instalação do regime militar no Brasil em meados da década de 1960 (Golpe Militar de 1964), quando um dos principais desdobramentos em nosso campo educacional foi o Acordo entre o nosso Ministério da Educação e Cultura (MEC) e a United States Agency for International Development (USAID), conhecido como Acordo MEC-USAID e tornado público no ano de 1966, tendo como objetivo central promover a reforma do ensino brasileiro.

A mudança da estrutura e da duração dos níveis de escolarização foi um dos principais resultados desse Acordo, que culminou com a Reforma Uni- 
versitária e decorrente implantação do ciclo básico. A reação da sociedade brasileira ao Acordo e às suas implicações obrigou o governo militar a uma série de concessões, que atenuaram várias diretrizes da proposta original, entre elas a privatização de todo o nosso ensino público. Todavia, persistiram várias repercussões diretas e indiretas do Acordo, entre elas a criação das Licenciaturas de Curta Duração em substituição às Plenas e a importação de projetos curriculares norte-americanos, voltados principalmente para os vários ramos das ciências da natureza, que foram traduzidos e adaptados para o ensino médio brasileiro.

No mesmo período, é criada a Fundação Brasileira para o Desenvolvimento do Ensino de Ciências (FUNBEC), em 1967, sediada também no campus da USP-São Paulo, que passou a atuar em parceria com o IBECC, com atribuições de fabricar e comercializar os recursos didáticos concebidos nos projetos desenvolvidos ou adaptados por este último. Também em meados da década de 1960, são criados pelo MEC seis Centros de Ciências distribuídos em diferentes regiões do país, sendo um deles na cidade de São Paulo, denominado Centro de Treinamento de Professores de Ciências do Estado de São Paulo (CECISP), também localizado no campus da USP e sediado no mesmo edifício que o IBECC e a FUNBEC, com a função principal de treinar os professores para a implementação dos novos projetos curriculares e materiais didáticos destinados à renovação do ensino das ciências da natureza e da matemática. Essas três instituições, com a colaboração dos cinco demais Centros de Ciências, constituíram a ponta de lança das iniciativas de mudanças no ensino de Ciências, impulsionadas naquela época principalmente pelo Acordo MEC-USAID (Fracalanza 1993).

$\mathrm{Na} 1^{a}$ fase de atuação conjunta e articulada de tais instituições, basicamente na $2^{\mathrm{a}}$ metade da década de 1960, o direcionamento principal das atividades foi a tradução, adaptação, difusão e treinamento docente de projetos curriculares para o ensino médio nas áreas de física (PSSC), química (CBA e CHEM Study), biologia (BSSC, nas versões azul, verde e amarela). No tocante às geociências, ocorreu uma peculiaridade: a versão preliminar do Earth Science Curriculum Project (ESCP) foi fruto da colaboração entre o CECISP e a Escola Preparatória de Cadetes da Aeronáutica (EPCA), de Barbacena, MG. Somente ao final dos anos 1960 e início dos anos 1970, foi desenvolvida a tradução e adaptação da versão final do ESCP, designada no Brasil como
Investigando a Terra. Embora todos esses projetos curriculares apresentassem suas particularidades, havia três características principais e inovadoras comuns: tratar de conteúdos essenciais do ramo do conhecimento científico tratado, expressos sinteticamente nos chamados temas unificadores; metodologia do ensino assentada fundamentalmente na experimentação; apresentar, além do Livro do Aluno, o Livro do Professor, em volumes independentes (Amaral 1995).

A década de 1960 também se caracterizou pelo início da tomada de consciência do advento da crise ambiental. A questão, antes restrita a círculos acadêmicos especializados e a algumas organizações ambientalistas ativistas radicais, ganha domínio público com a publicação em 1962 da obra Primavera Silenciosa, escrita pela bióloga norte americana Rachel Carson, sobre os efeitos ambientais do uso de agrotóxicos. Nos anos seguintes, tanto nos Estados Unidos da América, quanto na Europa, ocorre a publicação de outras obras ligadas à ecologia e aos problemas ambientais emergentes, evidenciando um estágio latente da temática ambiental. A década culmina com a constituição do Clube de Roma e publicação da obra Limites do Crescimento (1972), apresentando as reflexões e conclusões do encontro realizado na Itália, reunindo cientistas e empresários, preocupados com a questão ambiental decorrente do aumento da população mundial (Amaral 1995).

Ainda na década em foco e particularmente no âmbito das ciências geológicas ocorreram dois acontecimentos relevantes que merecem particular destaque, em virtude de suas afinidades com o movimento inovador do ensino das Geociências em nosso país, focalizado nesta comunicação, e suas repercussões futuras no mesmo. O primeiro deles foi a publicação nos Estados Unidos da obra The Fabric of Geology (Albritton Jr. 1963), uma coletânea de artigos de cunho filosófico, redigidos por diversos especialistas na área e organizada pela Geological Society of América, visando o reexame do estatuto epistemológico da Geologia, tendo em vista alicerçar mudanças no ensino dessa área do conhecimento. Quase contemporaneamente, é lançada a obra soviética The Interaction of Sciences in the Study of the Earth, também uma coletânea de artigos de diversos autores, onde se destaca o trabalho de M. S. Potapova (1968), que apresenta a geologia como a ciência histórica da natureza, contrariando os modelos vigentes que a entendiam como uma somatória da geologia física e a geologia 
histórica. Na nova concepção, todos os ramos da geologia física apresentam uma relação de subordinação em relação à geologia histórica e é justamente o seu caráter histórico que garante a especificidade da geologia como ciência.

A década de 1960 também foi pródiga em ideias inovadoras no campo pedagógico, com implicações importantes no âmbito do ensino-aprendizagem. Alguns autores, particularmente, além de sua relevância intrínseca, repercutiram significativamente no direcionamento das mudanças postas em prática na experiência educacional ora relatada. Dentre estes, merecem destaque: P. Freire (1971), J. Bruner (1972), J. Piaget (1973), L. Legrand (1973), B. F. Skinner (1973), G. Snyders (1974), C. Rogers (1975). Apesar de as respectivas ideias estarem assentadas em bases epistemológicas, psicológicas e sociológicas diferentes, em diversos aspectos até conflitantes, os citados autores foram apropriados pelas mudanças curriculares concebidas e implementadas na GGG-121.

A mencionada chegada ao Brasil, na segunda metade dos anos 1960, via FUNBEC e CECISP, da Versão Preliminar do ESCP, com sua publicação pela EPCA, e o início da tradução e adaptação da Versão Final do referido projeto curricular, criaram as condições materiais e inspiradoras para os primeiros ensaios de mudança no ensino da geologia introdutória, via os cursos de Licenciatura Curta em Ciências no estado de São Paulo. Muitas das ideias curriculares de alguns dos citados educadores já vieram impregnadas na estrutura programática e metodológica do ECSP, enquanto outras foram gestadas e incorporadas nas diferentes experiências pioneiras de adoção do ESCP nas disciplinas de geologia introdutória no ensino superior paulista.

\section{Anos 70: antigas e novas raízes do deflagrar do processo de inovação no Ensino das Geociências}

A década de 1970 iniciou com o ESCP em franca difusão, tanto nas disciplinas de geologia introdutória de diversas Licenciaturas Curtas de Ciências do estado de São Paulo, geralmente dispondo de uma carga horária de 180 a 240 horas, distribuídas em disciplinas em três ou quatro semestres, recebendo uma ênfase equivalente às que eram conferidas às biociências, à física e à química. Esta tendência se contrapunha ao modelo curricular tradicional, em que o conteúdo geológico parti- cipava da formação do professor de Ciências por intermédio de uma única disciplina semestral de 60 horas, cujo conteúdo tradicional se restringia a noções breves de geologia física e histórica, às vezes com pinceladas de mineralogia e paleontologia.

Essa mudança de perspectiva curricular ocorria particularmente naquelas Faculdades em que os professores responsáveis pelas disciplinas de Geociências pertenciam também à equipe técnica da FUNBEC que realizava a tradução e adaptação do projeto ESCP, assim como de sua difusão junto a professores das séries finais do ensino fundamental (antigo $1^{\circ}$ grau) e especialmente do ensino médio (antigo $2^{\circ}$ grau) das disciplinas de ciências físicas e naturais, que entravam em contato com o projeto por intermédio de numerosos cursos de treinamento proporcionados pelo CECISP.

O interesse pelas Geociências como componente curricular independente no ensino básico aumentava. Dois sinais importantes davam consistência a essa afirmação: criação de uma disciplina optativa de Geociências no currículo do ensino médio oficial e a abertura de uma Licenciatura em Geologia na Faculdade de Educação da USP. Acrescente-se a isso o interesse crescente de professores de Ciências, que passavam pelos treinamentos do CECISP ou que se graduavam nas mencionadas Licenciaturas Curtas inovadoras, em ampliar os tópicos de Geociências na disciplina de Ciências que ministravam em escolas públicas. Tanto as disciplinas de Geociências dessas Licenciaturas, quanto os cursos de treinamento em ESCP oferecidos pelo CECISP, entre diversas novidades, convenciam os docentes de que as geociências não se confundiam com a geografia física, nem estavam satisfatoriamente contempladas nessa disciplina do ensino fundamental e médio. Além disso, tinham uma área de abrangência temática mais ampla do que a geologia. Ficava claro que o enfoque das geociências tinha muito maior afinidade com as ciências físicas e naturais, em cujo âmbito poderia dividir espaço com as biociências, a física e a química (Amaral 1995).

A curiosidade e admiração despertadas pelo modelo curricular do ESCP foram provavelmente favorecidas pelas suas características interdisciplinares, em um momento histórico em que as questões da fragmentação do conhecimento e da forma equivalente com que eram inseridos nos programas escolares começavam a ganhar destaque nos meios científicos e educacionais, embalados pelas ideias ambientalistas em acentuada propagação (Haggis e 
Adey 1979, UNESCO/Unep 1985). A proposta do ESCP, de reunir conhecimentos físicos, químicos, biológicos, geológicos e astronômicos voltados para o estudo do planeta Terra, configurava-se até então como o modelo mais avançado de integrar os conteúdos curriculares das ciências da natureza, ao mesmo tempo em que possibilitava compreensão mais plena e articulada da dinâmica da natureza terrestre (Amaral et al. 1976, Carneiro e Negrão 1995).

No início de 1973, foi publicado o Volume 1 da versão brasileira definitiva do ESCP, denominada Investigando a Terra, preparada por equipe da FUNBEC. Constituiu elemento especialmente facilitador para a experiência de renovação então em vias de ser implantada no IG-USP. Em 1976, foi publicado o Volume 2, sendo que ambos foram editados com seus respectivos volumes independentes do Livro do Aluno e Livro do Professor. Foram acompanhados pela disponibilização comercial de kits variados de material didático, para serem utilizados em atividades práticas, de experimentação ou não, previstas na obra, em sua versão brasileira.

Enquanto esses acontecimentos todos se desenrolavam nos cenários nacional e/ou internacional, o ensino de geologia básica na USP, destinado a alunos de vários institutos e sob a responsabilidade do Instituto de Geociências, estava em plena crise operacional e de identidade, fosse por motivos organizacionais, fosse por obsolescência programático-metodológica diante das novas exigências históricas. Havia dificuldades logísticas para fazer frente ao grande contingente de cerca de quinhentos alunos anuais, havia dificuldade em equacionar os interesses e necessidades diversificados dos alunos procedentes de vários cursos de graduação, a maior parte em caráter obrigatório, mas também atraindo um apreciável contingente optativo. Estava, assim, inequivocamente configurada uma crise que abriu as portas para a inusitada experiência de renovação programática, metodológica e logística, no campo curricular da geologia introdutória no ensino superior, objeto central desta comunicação. $\mathrm{O}$ centro do processo foi a disciplina Geologia Geral (GGG121), na qual desaguaram os resultados que haviam sido obtidos nas iniciativas até então restritas às licenciaturas curtas, que apresentavam condições muito peculiares de abertura para a inovação. Pela primeira vez um gigante de tradição e conservadorismo se abria a ideias educacionais heterodoxas e inovadoras para seus padrões.

O primeiro passo foi escolher um profissional que viesse a coordenar a mudança. Por diversos motivos, considerou-se que deveria ser alguém que ainda não pertencesse aos quadros do IG e que militasse em questões educacionais das geociências. O convite foi feito para um jovem geólogo, especializado em ensino da geologia introdutória, coordenador da elaboração da versão brasileira do ESCP junto à FUNBEC/CECISP e com experiência de docência e implementação desse currículo em licenciaturas curtas de Ciências. O convite foi por mim aceito mediante algumas exigências, entre elas a preparação prévia da equipe docente que iria atuar na GGG-121, a partir do $1^{\circ}$ semestre de 1973. Algumas resistências internas tiveram que ser superadas com firmeza e determinação pela direção do Departamento de Geologia Geral, ao qual a disciplina estava vinculada. Nos dois meses iniciais daquele ano, o futuro corpo docente entrou em contato e vivenciou em detalhes a proposta programático-metodológica do ESCP e, coletivamente, participou da sua adaptação à realidade da GGG-121. A esta equipe viria a se juntar um grupo de monitores (alunos de pós-graduação e graduação em geologia), para o desenvolvimento das aulas, formando duplas com os docentes do Instituto, que se responsabilizaram por cada uma das dez turmas (diurnas e noturnas) que cursariam a disciplina.

Assim, foram dados os primeiros passos para enfrentar a crise do ensino básico da geologia na USP e para que a GGG-121 viesse a se transformar em um desaguadouro do modelo ESCP no ensino superior brasileiro, apropriando-se dos conhecimentos extraídos das aplicações anteriores do mesmo nas licenciaturas curtas de Ciências. A inovação posta em prática na ocasião assumiu diversas características peculiares, que foram sendo aperfeiçoadas nos anos subsequentes, mas que assim se consubstanciaram basicamente:

- Adoção da sistemática de trabalho em equipe, na preparação, desenvolvimento e avaliação das aulas e do curso como um todo. A primeira versão do curso foi preparada semanalmente, aula a aula, em reuniões com a participação de docentes e monitores. Cada aula ministrada também era subsequentemente avaliada por todos e as observações constituíam um dossiê a ser levado em conta nas reformulações do semestre seguinte, após a sistematização das avaliações levadas a efeito junto aos alunos. Anualmente, as mudanças eram mais drásticas, configurando novas versões do curso, que só vieram a se consolidar no quinto ano da experiência, coincidentemente o último ano de sua existência. 
- Adoção do modelo programático e metodológico do ESCP, com as devidas adaptações para a realidade em foco. Isto significou substituição: (a) do conteúdo clássico de Geologia Geral ou de Geologia Física pelas Geociências; (b) da visão cartesiana e moderna da ciência, por um enfoque crítico da atividade e do conhecimento científicos e do seu papel social; (c) dos conteúdos centrados em conceitos por conteúdos centrados em fenômenos; (d) da metodologia de ensino centrada em aulas expositivas e atividades práticas demonstrativas, aplicativas ou ilustrativas da teoria, por atividades teóricas e práticas sem sequência hierárquica e entrelaçadas no processo de ensino-aprendizagem; (e) do aluno receptor passivo pelo aluno ativo e participativo; (f) da avaliação somativa pela avaliação formativa. Acrescente-se a isso a decisão de substituir o critério de constituição das turmas: ao invés de classes constituídas por alunos exclusivos de cada graduação envolvida, adotou-se a formação de classes mistas, organizadas segundo desempenho dos alunos em pré-teste, o que propiciava a adoção de um planejamento de aulas adequado a cada turma, embora se perdesse a especificidade dos diferentes cursos de origem dos estudantes.

- Impregnação de todo o conteúdo programático e da metodologia de ensino pela questão ambiental, tomada em suas múltiplas dimensões, inclusive as externas às geociências e mesmo às ciências da natureza. Tratava-se de um encaminhamento pioneiro para a época, mas facilitado pelo enfoque dado pelo ESCP à dinâmica da natureza e pela literatura ambientalista em plena emergência no período.

- Adoção de currículo integrado dos conteúdos abrangidos pelas geociências, que ultrapassava em muito as configurações curriculares compartimentadas, atreladas aos modelos de Geologia Geral e Geologia Física, adotados até então (Amaral 1981). Novamente, a iniciativa se apoiava no próprio modelo do ESCP, assim como era influenciada pelas discussões internacionais de vanguarda nos campos educacional e ambiental, que sinalizavam para a perspectiva interdisciplinar. A estrutura interdisciplinar se apoiava em temas unificadores, a maioria deles originais do próprio ESCP: universalidade da transformação; fluxo de energia no universo; adaptação à transfor- mação do meio; conservação da massa e da energia no universo; sistemas terrestres no espaço e no tempo; uniformidade dos processos como chave para interpretar o passado; homem como agente geológico. Particularmente este último tema foi gestado no interior da disciplina, funcionando como ponte entre as geociências, a perspectiva interdisciplinar e o enfoque ambiental. Além disso, outro alicerce marcante dessa visão interdisciplinar advinha da incorporação da visão de geologia como ciência histórica da natureza, por sua vez apoiada no enfoque das geociências como visão integrada da dinâmica da natureza no presente geológico.

Ao longo dos cinco anos que durou a experiência de renovação em foco, o curso foi sofrendo reformulações decorrentes do estilo de atuação coletiva e crítico-reflexiva adotado pela equipe docente e influenciadas pelas literaturas: de caráter pedagógico de vanguarda na época (exemplificada anteriormente); da nova filosofia da ciência em ampla expansão no período (por exemplo: Hempel 1970, Bacchelard 1972, Deus 1974, Kuhn 1975, Dixon 1976, Feyerabend 1977); da epistemologia da geologia posta em discussão por autores norte-americanos e soviéticos, além de alguns brasileiros (por exemplo: Potapova 1968, Shantzer 1968, Simpson 1970, Avanzo 1974); da onda ecológica e ambientalista, difundidas por obras traduzidas e publicadas em numero crescente na década $70 \mathrm{em}$ nosso País, tais como: Prat (1971), Toffler (1972), Meadows et al. (1972), Ward e Dubos (1973), Dorst (1973), Dubos (1974), Ehrlich e Ehrlich (1974), Liebman (1976). Em sintonia com esta nova onda, destacavam-se obras no campo das geociências, tais como: American Geological Institute (1970), Strahler e Strahler (1973), Tank (1973), Herrera (1974), Young (1975), Cargo e Mallory (1977). Vinte e três participantes, entre docentes e monitores, fizeram parte da equipe que idealizou, elaborou e levou à pratica o novo curso. Os resultados da experiência de renovação programática e metodológica na disciplina introdutória de geologia na USP foram formalizados em um conjunto de roteiros de ensino e aprendizagem, produzidos para cada aula, revistos a cada ano e publicados em sua última versão (1976) em único volume, sob o título de Guias Metodológicos para Aprendizagem de Geologia Geral (Amaral et al. 1979).

Conflitos e descompassos entre o estilo de trabalho adotado na GGG-121 e os interesses 
predominantes no IG-USP inviabilizaram a continuidade e expansão da experiência renovadora, redundando na saída de toda a equipe docente no início de 1978. Na época, a evolução das ideias da equipe tinha levado à necessidade de produção de nova proposta curricular para o que passávamos a denominar de Geologia Introdutória no ensino superior, que consistia numa superação programática e metodológica do modelo do ESCP. Adotou-se a designação genérica de Geologia Introdutória para todas as disciplinas encarregadas de apresentar o conteúdo geológico aos estudantes do nível superior, independente do enfoque programático por elas adotado. O novo projeto, denominado Projeto de Ensino de Geologia Introdutória (PEGI), foi enviado a órgãos financiadores e teve seu pedido aprovado logo após a saída da equipe do IG-USP.

\section{Anos 80: abertura de novos horizontes e desdobramentos}

Com a extinção das condições favoráveis para a permanência e a expansão da experiência inovadora no ensino de geologia introdutória na USP, buscaram-se outros espaços, que pudessem abrigar o trabalho em suas novas perspectivas. Após negociações malogradas com instituições universitárias de vários cantos do país, a equipe momentaneamente se dispersou, ao mesmo tempo em que buscava uma nova sede para o PEGI. Circunstâncias oportunas levaram à transferência do projeto recém-financiado para a Faculdade de Educação da Unicmp e posteriormente, por intermédio de convênio interno, para um processo de cooperação com o recém-criado Instituto de Geociências. Parte da equipe original da GGG-121 veio a integrar o grupo responsável pelo PEGI. Todavia, devido à dispersão de recursos financeiros, para atender a exigências político-acadêmicas, não foi possível concluir o PEGI, mas que teve suas idéias e proposições disseminadas em iniciativas junto à SBG e ao próprio IG-Unicamp, por via da sua recém-criada Área de Educação Aplicada às Geociências.

As ideias e práticas educacionais em geociências adotadas na USP já haviam repercutido na comunidade geológica desde seu início, por intermédio da Sociedade Brasileira de Geologia (SBG) e de Simpósios específicos de ensino, por ela organizados durante seus Congressos Brasileiros de Geologia. Além das questões metodológicas de ensino, ganhava realce nos eventos a problemática curricular, que culminaria ao final dos anos 1970 e início de 1980 em uma grande campanha nacional, sustentada por pesquisa diagnóstica, levada a efeito pela Comissão Nacional de Ensino da SBG, visando retratar os vinte anos de cursos de Geologia no país e delinear diretrizes para mudanças curriculares na formação do geólogo (Amaral et al. 1981). Nesse intervalo, as novas concepções de geologia enquanto ciência e de ensino de geologia haviam se impregnado em todo o movimento nacional em prol da reformulação do currículo de graduação da Geologia. Uma iniciativa fundamental para a sobrevivência e consolidação dessas ideias e práticas foi a realização em 1979 do Curso de Especialização em Ensino Superior de Geociências, junto ao corpo docente do Curso de Geologia da Universidade Federal do Pará, a convite dessa instituição, ministrado pelos docentes que haviam levado a efeito a experiência da USP. Foi uma oportunidade única para ultrapassar os limites da geologia introdutória e formalizar bases e diretrizes para uma nova visão do ensino da geologia como um todo, nas suas diferentes disciplinas, e da formação do geólogo brasileiro. Muitas das ideias e propostas desenvolvidas no Curso de Especialização foram disseminadas em diferentes teses propostas nos mencionados Simpósios Nacionais $(1981,1982,1983)$ que viriam a discutir a nova formação do geólogo brasileiro.

Fatores políticos internos e externos à comunidade geológica impediram a adoção das recomendações e da proposta curricular discutidas e aprovadas em encontro nacional, organizado pela SBG e promovido pelo Ministério da Educação e Cultura (MEC), especialmente organizado para essa finalidade, e com a representação paritária de setores profissionais, docentes, estudantis e institucionais (Sociedade Brasileira de Geologia 1983).

Os obstáculos não foram suficientes para dissolver o legado da experiência da USP. Nesse período, professores que haviam participado e/ ou haviam coordenado as iniciativas da USP e da SBG passaram a fazer parte do quadro docente da Unicamp, colaboraram intensamente na criação do Instituto de Geociências dessa universidade e foram idealizadores de uma da Área de Educação Aplicada ao Ensino de Geociências (AEAG) no referido Instituto. Uma das primeiras iniciativas da Área foi a criação regular do Curso de Especialização em Ensino Superior de Geociências, frequentado em suas diversas ofertas por professores de disciplinas geológicas de todo o país (Negrão, org. 1990). Por seu intermédio, ocorreu 
o amadurecimento e disseminação das concepções de geologia como ciência e de ensino de geologia, que haviam sido gestadas duas décadas antes no IG-USP. A consolidação permanente desse grupo de geólogos, que haviam escolhido se tornar docentes pesquisadores dedicados à questão da educação em geologia, ocorreu com a institucionalização do IG-Unicamp e a concomitante transformação da AEAG no Departamento de Geociências Aplicadas ao Ensino (DGAE), a criação pioneira do mestrado e doutorado em ensino de geologia e sua posterior transformação no Programa de Pós-Graduação em Ensino e História de Ciências da Terra (PEHCT).

Um legado curioso, singular, e até certo ponto inesperado, foi a influência que essas idéias educacionais, particularmente no âmbito da geologia introdutória, tiveram na reformulação curricular de Ciências do estado de São Paulo, na década de 1980, conferindo às geociências, no novo currículo de Ciências, um caráter estruturante dos conteúdos programáticos, proporcionando nova e contemporânea visão do que poderia ser ensinar Ciências na escola fundamental (São Paulo 1988, Amaral 1991). Todavia, tal acontecimento não foi fortuito.

Primeiramente, é fruto do resgate de estudos, reflexões e proposições apresentados na I Jornada Sobre o Conteúdo Geológico nos $1^{\circ}$. e $2^{\circ}$. Graus, encontro organizado pela Sociedade Brasileira de Geologia em Belém do Pará, em 1983 , cujos Anais foram publicados pela SBG em 1984. Finalmente, deve-se à presença, na assessoria da elaboração da Proposta Curricular de Ciências, de docentes direta ou indiretamente vinculados à implementação do ESCP no Brasil e dos seus sucedâneos, entre eles o inconcluso PEGI (voltado ao ensino superior), na década de 1980, e de seu precursor PEGE (voltado ao ensino de $1^{\circ} \mathrm{Grau}$ ), na década de 1970 , também inconcluso, concomitante à experiência da USP. Apesar de terem sido inconclusos, ambos deixaram significativo acervo de reflexões e propostas sobre como deveriam ser a participação da geologia e das geociências no ensino fundamental, que deram ricas contribuições aos princípios e diretrizes adotados na reformulação curricular de Ciências no estado de São Paulo. Surpreendentemente, a conquista desse espaço curricular, tão almejado por alguns setores da comunidade geológica brasileira, passou praticamente despercebida pela mesma, apesar de a Proposta haver vigorado por cerca de vinte anos (1988 a 2008).

\section{Conclusões}

A narrativa desenvolvida em torno das experiências inovadoras vinculadas ao ensino da geologia introdutória e de alguns de seus desdobramentos permite derivar algumas importantes conclusões:

- A inovação educacional é um processo complexo que se beneficia profundamente do trabalho coletivo e do envolvimento autêntico das comunidades diretamente interessadas, se possível com a colaboração das associações de classe. Momentos de crise favorecem sobremaneira as iniciativas de mudança, desde que construam respostas convincentes aos novos desafios e seus atores saibam como enfrentar as tradições culturais e a resistência dos setores conservadores.

- As inovações não podem obedecer a impulsos circunstanciais e a ideias improvisadas, mas devem se inspirar em estudos de especialistas das diversas áreas de conhecimento que confluem e dão sustentação ao fenômeno educativo. Além disso, não bastam boas ideias e boas intenções para sobrevivência de experiências de sucesso, sendo necessárias persistência e força política.

- Modelos curriculares preparados para outras realidades podem contribuir com idéias e soluções inovadoras, mas precisam passar pelo filtro de cada circunstância espacial e temporal, ganhando contornos que reflitam as necessidades e exigências do momento histórico e do desafio concreto em que se situam.

- A geologia introdutória consiste em uma designação genérica que pode adquirir delineamentos programáticos variados, mas que em uma perspectiva contemporânea é mais bem representada pela geociências impregnada das dimensões ambiental e histórico-geológica.

- A geologia tomada em seu sentido de ciência histórica da natureza contribui de forma marcante para atribuir ao ensino fundamental das ciências da natureza uma perspectiva interdisciplinar do ambiente terrestre e um enfoque sistêmico do nosso planeta, o que a torna um veículo singular e valioso na formação de futuras gerações para o enfrentamento da crise ambiental.

- O sistema educativo formador do professor de Ciências está bastante distante da visão aqui preconizada para a geologia introdutória e para o seu papel no ensino de ciências, destacando- 
-se pelo caráter fragmentário e compartimentado dos conhecimentos físicos, químicos, biológicos e geológicos. A comunidade geológica ainda não despertou efetivamente para esse importante papel social e para essa oportunidade profissional.

\section{Referencias Bibliográficas}

Albritton Jr. C.C. ed. 1963. The Fabric of Geology. Massachussets: Addison-Wesley Publ. Co.

Amaral I.A.do. coord. 1975. Investigando a Terra (ESCP). São Paulo: McGraw Hill do Brasil / FUNBEC, Vol. 1 do Aluno. 435p.

Amaral I.A.do. coord. 1979. Guias metodológicos para a aprendizagem de Geologia Geral. Campinas: Fac. Educ. Unicamp. 157p.

Amaral I.A.do. 1981. O Conteúdo e o enfoque dos livros de geologia introdutória. São Paulo: IG/USP. 259p. (Dissert. Mestr.).

Amaral I.A.do. 1991. Ambiente, educação ambiental e ensino de Ciências. In: Lima M.M.S.de, Kiouranis N.M.M., Gonçalves R.C.E.G., Alencar S.M.A. Ciências na escola de $1^{\circ}$ Grau. Textos de apoio à proposta curricular. São Paulo: Secret. de Est. Educação / Coord. Estudos e Normas Pedagógicas. p. 39-62.

Amaral I.A.do. 1995. Em busca da planetização: do ensino de ciências à educação ambiental. Campinas: Fac. Educ. Unicamp. 434p. (Tese Dout.).

Amaral I.A.do, Macedo A.B., Carneiro C.D.R. 1976. Uma busca de renovação no ensino de Geociências. Bol. Paul. Geogr., (52):55-68.

Amaral I.A.do, Manfredi S.M., Negrão O.B.M. 1981. A formação do geólogo nas universidades brasileiras: um retrato de duas décadas. Brasília: MEC e Soc. Bras. Geol. 209 p.

American Geological Institute. AGI. 1970. Environmental geology. Washington: Am. Geol. Inst. $430 \mathrm{p}$.

Avanzo P.E. 1974. Geociências: uma nova maneira de ver a Terra. In: Geologia, Ciência e Técnica. São Paulo: CEPEGE, (4):17-24.

Bachelard G. 1972. Conhecimento comum e conhecimento científico. Rio de Janeiro: Rev. Tempo Brasileiro. (28):27-46.

Bruner J. 1976. O Processo da educação. São Paulo, Melhoramentos.

Cargo D.N., Mallory B.F. 1977. Man and his geologic environment. Massachusetts: Addison-Wesley. 565p.

Carneiro C.D.R., Negrão O.B.M. 1995. Busqueda incessante. Rev. de la Enseñanza de las Ciencias de la Tierra, 3(1):61-62. URL: http://www.raco.cat/ index.php/ECT/article/view/89237/141665. Acesso 18.03.2010.

Carson R. 1962. Primavera silenciosa. São Paulo: Ed. Melhoramentos. 365p.
Deus J.D. org. 1974. A Crítica da ciência. Rio de Janeiro: Zahar.

Dorst J. 1973. Antes que a natureza morra: por uma ecologia política. São Paulo: Edgar Blücher/EDUSP.

Dubos R. 1974. Um animal tão humano. São Paulo, Melhoramentos/EDUSP.

Ehrlich P.R., Ehrlich A.H. 1974. População, recursos e ambiente. São Paulo: Polígono. 509p.

Feyerabend P. 1977. Contra o método. Rio de Janeiro, Francisco Alves.

Fracalanza H. 1993. O que sabemos sobre os livros didáticos para o ensino de Ciências no Brasil. Campinas, Fac. Educ. Unicamp. (Tese Dout.).

Freire P. Educação como prática de liberdade. Rio de Janeiro, Paz e Terra. 1971, $150 \mathrm{p}$.

Haggis S., Adey P. 1979. A review of integrated science education world-wide. Studies of Science Education, (6):69-89.

Hempel C. 1970. Filosofia da ciência natural. Rio de Janeiro, Zahar.

Herrera A.O. 1974. Los recursos minerales y lós limites Del crecimiento econômico. Buenos Aires, Siglo Veinteuno. 1 82p.

Kuhn T. 1975. Estrutura das revoluções científicas. São Paulo: Perspectiva. 257p.

Legrand L. 1973. Didática da reforma. Rio de Janeiro, Zahar.

Liebman H. 1976. Terra, um planeta inabitável? São Paulo. Melhoramentos/EDUSP. 180p.

Meadows D.H., Meadows D.L., Randers J. e Beherens, W.W. 1972. Limites do crescimento. São Paulo: Perspectiva. $246 \mathrm{p}$.

Negrão O.B.M., Fonseca M.A. coords. 1976. Investigando a Terra (ESCP). São Paulo: McGraw Hill do Brasil / FUNBEC, Vol. 2 do Aluno. 240 p.

Negrão O.B.M. org. Especialização em ensino de geociências no $3^{\circ}$. grau. In: Anais do Simpósio. Campinas, AEAG/IG/Unicamp. 1990, 178 p.

Piaget J. 1973. Psicologia e epistemologia. Rio de Janeiro, Forense.

Prat H. 1971. La metamorfosis explosiva de la humanidad. Barcelona, Plaza e Janes. 253p.

Potapova M.S. 2008. Geologia como uma ciência histórica da natureza. Terrae Didatica, 3(1):86-90. [Trad. de: Potapova M.S 1968. Geology as an historical science of nature. In: Interaction of the science in the study of the Earth. Moscow: Progress, p.117126]. URL: http://www.ige.unicamp.br/terraedidatica/v3/v3 a7.html. Acesso 27.02.2014.

Rogers C. 1975. Liberdade para aprender. Belo Horizonte, Interlivros.

São Paulo, Secretaria Estadual da Educação 1988. Proposta curricular para o ensino de ciências e programas de saúde. 1․ Grau. São Paulo: CENP. 58p.

Shantzer Y.V. 1968. Modern Geology and its place among the natural ciences. In: Interaction of sciences in the study of the earth. Moscow, Progress. p. 92-116. 
Simpson G.G. 1970. La Ciência histórica. In: Filosofia de la geologia. México: Ed.Continental.

Snyders G. 1974. Pedagogia progressista. Coimbra: Almedina.

Skinner B.F. 1975. Tecnologia do ensino. São Paulo: EPU /EDUSP. 258p.

Sociedade Brasileira de Geologia (SBG). 1981a. Simpósio Nacional sobre o Ensino de Geologia no Brasil 1. 1981 Belo Horizonte. Teses. São Paulo: Sociedade Brasileira de Geologia 2v. 268p.

Sociedade Brasileira de Geologia (SBG) 1983. Simpósio Nacional sobre o Ensino de Geologia no Brasil. Currículo Mínimo, 2. 1982, Salvador. Documento Final. São Paulo: SBG. 73p.

Sociedade Brasileira de Geologia (SBG) 1984. Anais da I Jornada sobre o Ensino do Conteúdo Geológico nos
$1^{0}$ e $2^{0}$ Graus, 1983. Belém, São Paulo: SBG.61p.

Strahler A.N., Strahler A.H. 1973. Environmental geosciences: interaction between natural system an man. New York: John Wiley \& Sons. 511p.

Tank R.W. org. 1973. Focus on environmental geology. New York: Oxford Univ. Press.

Toffler A. 1973. O choque do futuro. Rio de Janeiro, Artenova. 405p.

Organização das Nações Unidas para a Educação, a Ciência e a Cultura UNESCO/Unep. 1985.L'aproche interdisciplinaire en education relative a l'environnement. Paris: Unesco.

Young K. 1975. Geology: the paradox of earth and man. Boston: Houghton Mifflin. 526p.

Ward B., Dubos R. 1973. Uma Terra somente. São Paulo: Edgar Blücher/Melhoramentos/EDUSP. 277p.

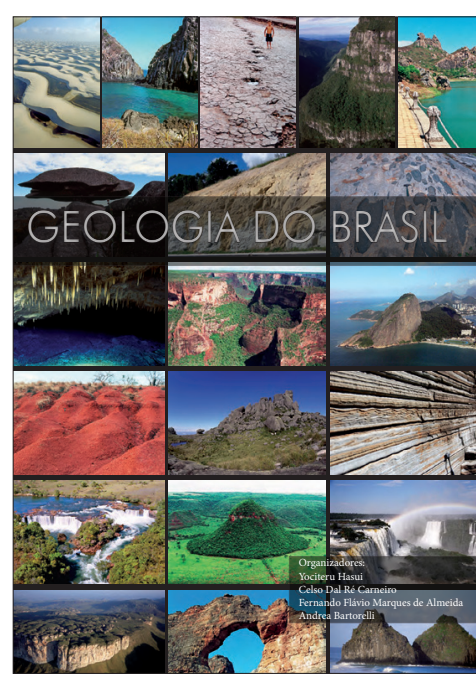

Geologia do Brasil reúne pesquisadores de diferentes áreas da Geologia em uma publicação que apresenta e atualiza o conhecimento geológico, de forma completa e didática, para estudantes e profissionais da área. Convidamos o leitor a apreciar esse conjunto de informações e conceitos, tanto pela beleza do conhecimento em si, quanto pela necessidade de revisitar o território brasileiro.

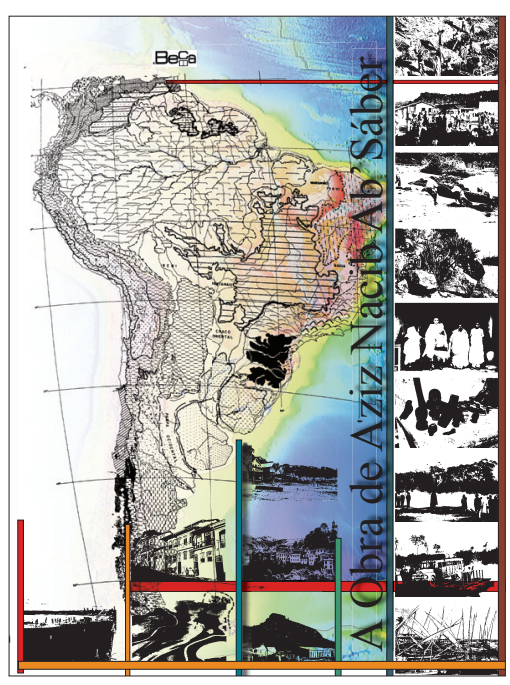

Reunião da obra acadêmica do geógrafo Aziz Nacib Ab'Sáber. No DVD anexo, documentário, registro do encontro com Fernando Flávio Marques de Almeida, e acervo de fotos das décadas de 1950 e 1960, além de mais de quatrocentos artigos publicados pelo autor (em formato PDF), incluindo textos inéditos, com possibilidade de busca simultânea.

\section{.Beㅁa}

http://www.editorabeca.com.br jvendas@editorabeca.com.br (11) 3141-1291 